\title{
Expand or Oversize? Planning Internet Access Network in a Demand Growth Scenario
}

\author{
Matheus Pereira Libório ${ }^{1}$ (D) - Petr lakovlevitch Ekel ${ }^{1}$ (D) Renata de \\ Mello Lyrio $^{2,3}$ (D) Patrícia Bernardes ${ }^{1}$ (D) . Gustavo Luís Soares ${ }^{1}$ (D) \\ Thiago Melo Machado-Coelho ${ }^{3}$
}

Received: 27 January 2020 / Revised: 18 May 2020 / Accepted: 30 July 2020 / Published online: 13 August 2020

(c) Springer Science+Business Media, LLC, part of Springer Nature 2020

\begin{abstract}
Internet network design specialists are looking for technologies and strategies to deliver network service under increased demand conditions. The choice of strategies is based on applying optimization and decision-making methods to select the most appropriate cable network design considering criteria established by the problem definition. However, this definition is itself a decision problem that has not received analysis in the literature. In particular, one of the most important questions is the necessity to define an expansion strategy. The first alternative (expansion) is to design a network to serve consumers with Internet demand equal to or greater than the predefined one to expand the network annually to serve consumers that reach the predefined Internet speed. The second alternative (oversizing) is to design a network to serve consumers with future Internet demand (after 5 years) at or above that the predefined one. Considering this, the objective of this research is to define the most advantageous strategy of expansion planning to attend a 5 years forecasted Internet demand, considering: (1) the possibility of utilizing a Gigabit-capable Passive Optical Network technology; (2) the application of the minimal Steiner tree and Dijkstra algorithms in planning procedures; (3) the influence of economic and technological factors on the demand forecast; (4) the aggressive, moderate, and conservative scenarios in decision-making. The results show that the over-dimensioning strategy reduces network investment by between 30 and $41 \%$, but that this reduction does not always lead to a market investment ratio higher than that observed in the expansion strategy.
\end{abstract}

Keywords Internet forecast model · Geoprocessing · Optimization algorithms · Decision-making $\cdot$ Network planning strategies

Thiago Melo Machado-Coelho thmmcoelho@ufmg.br

Extended author information available on the last page of the article 


\section{Introduction}

Studies reveal that Internet-based services will face a very challenging scenario [1]. First, because Internet demand is growing driven by increasing customer numbers [2], by the emergence of new technologies [3-5], and by applications of the Internet of Things (IoT) and Smart Cities (SC) systems [6]. Second, because Internet networks are unable to serve new customers due to technological limitations [7, 8], approach their physical limitations [9, 10]. More than two distinct challenges, the opposite direction between declining network capacity and growing Internet demand [11] signals that the scenario ahead calls for an urgent solution: expanding (current or new) Internet networks. Considering that network planning is part of this solution, network planners play a relevant role in this context [2, 7, 12-14].

For the most part, the network planning literature is related to applying optimization methods $[3,11,12,15-21]$ to minimize investments in cables and equipment [5]. However, by focusing exclusively on investments, these studies disregard the growth in Internet demand over time that directly influences network designs. These studies take demand as stable or disregard the strategies generated by new Internet technologies [22, 23]. The strategies offered by the new technologies are not limited to offering high capacity and traffic scalability [4] but greater flexibility to expand the cable network and serve new customers [3].

With this possibility, network planners can: (I) expand the network by laying cables to serve new customers as these customers arise [2, 6]; or (II) oversize the network, leaving enough cables to serve new customers coming in the future [1]. With these alternatives, the question arises: which of these two strategies is most advantageous?

Unlike studies that focus exclusively on the volume of investments in the cable network [18], this research also takes into account the Internet demand per person and the size and positioning of the market [13], the bandwidth capacity to provide new services [24], and the network coverage for support of IoT and SC systems [14]. In summary, this research considers that the most advantageous planning strategy is defined both by investments and by the Internet demand per person and market. Thus, the most advantageous strategy is defined by the way in which the return on investments made [11], especially during the first years of the network's life when the ratio of market to investment is most essential [25].

The purpose of this research is to answer which is the most advantageous cable network planning strategy in a scenario of Internet market increase. For this statement, the literature on forecast models, flexible network technologies, and optimization algorithms are explored. The following is the case study in which, cable networks are designed for planning strategies to expand and oversize. These network designs are based on future Internet demand, forecasted from economic and technological variables, the market conditions (distribution and population concentration) [2], and on applying the Dijkstra [19] and Steiner tree [20] algorithms. Finally, the answer to the most advantageous cable network planning strategy is obtained by analyzing the ratio between Internet market and investment according three different scenarios of Internet offer. 


\section{Cable Network Planning Scenario}

In the early 2000s, the oversizing of Internet networks left equipment and cables underused for several years [1]. However, the ability to service these networks has not kept pace with the growth of Internet demand [11]. This hindered the recovery of investments made, especially as these networks approached their physical limitations [9] and were left without margin to generate new revenues and higher operating costs [10]. This was because the technologies of these networks were not fully flexible [8]. That is, if, on the one hand, the exchange of equipment allowed the increase of the bandwidth capacity, on the other hand, the cable network architecture limited the attendance of new customers, especially customers outside the cable network coverage area [7]. For these reasons, network planners have increasingly considered in their network planning strategies: I) Forecast of Internet demand [6, 26-29]; and II) the use of flexible technologies [15, 18, 21, 30].

Taking Brazil as an example, forecasts based on historical data show that Internet demand will reach $149.8 \mathrm{kbps}$ per person by 2022 [2]. However, research also shows that forecasting models based on historical data distort long-term Internet demand results [31]. Such distortions occur because Internet demand information on emerging technologies [32] (e.g., online games, video streaming [3, 5], cloud computing [4], and systems of IoT and SC [14]) is not present in historical data. In Brazil, researchers forecast that the interconnectivity between emerging technologies and IoT and SC innovations will boost Internet demand per person, making demand nearly double between 2016 and 2022 (98.5 kbps per person to $185.7 \mathrm{kbps}$ per person) [6]. This forecast is $24 \%$ higher than forecasts based on historical data [2] and reinforces the understanding that emerging technologies and IoT and SC systems can impact both long-term Internet demands forecasting results and planning strategy of new networks. This is because these networks must be designed to support billions of parallel sensor data streams [33], enable big data applications, process integrated real-time, high-speed data exchange [24], oversee the physical components of the system, ensure high levels of security [34], prevent spying and/or external attacks [35] and withstand high flash rates [4]. That is, Internet network planners should consider technology solutions that are adaptable to dynamic Internet demand scenarios [36] which suggest that: (I) $81 \%$ of Internet traffic will not originate from personal computers; (II) 28.5 billion devices will be connected, and III) the devices will consume in $2 \mathrm{~h}$ all Internet traffic currently consumed in one week [26].

Among current technologies, studies suggest that the Gigabit-capable passive optical network (GPON) [22] is a technology solution that is adaptable to the scenario of increasing Internet demand [18, 30, 37], and can be considered a proven solution of the future [3] for at least five reasons. First, GPON networks are immune to electromagnetic interference and do not require active components between a switch and a client [4]. Second, GPON networks allow service traffic originating from both mobile (5G) and cable networks [14]. ${ }^{1}$ Third, because GPON networks

\footnotetext{
${ }_{1}^{1}$ The understanding that 5G networks will replace GPON networks is not consolidated in the literature $[49,50]$. Researchers argue that the cost of transporting 5G networks encourages the reuse of infrastructure and the convergence between fixed and mobile access networks [51]. Comparative studies show that GPON networks are still less expensive and more profitable in the long run than 5G networks [52].
} 
offer abundant bandwidth capacity to support bandwidth-intensive services traffic [15]. Fourth, because GPON networks enable network traffic capacity to be increased by upgrading and/or adding equipment [27, 38]. Fifth, because GPON networks make it possible to serve new customers by laying cables from splitters $[22,23]$. In short, the characteristics of GPON technology favor the expansion of network capacity (traffic and/or new customers) to meet increased Internet demand regardless of the planning strategy (expand or oversize). But what is the most advantageous network planning strategy?

In general, network planning includes Internet demand forecast, geoprocessing the characteristics of the local analysis unit (city, neighborhood, etc.), and cable network design. Internet demand forecast involves variables that represent social conditions (e.g. macroeconomic aspects [29], technologies and innovations [39], the Internet availability $[40,41])$ and, the procedures adopted in this relatively fickle activity [1]. The geoprocessing of the physical characteristics of the unit of analysis involves variables that represent the occupation of the city (e.g., distribution and population concentration [2], the layout of streets and avenues [3, 12, 42, 43]) being procedures adopted in this activity relatively constant [44]. Network design involves cost-related variables (e.g. cable routing and equipment installation), not the relatively constant procedures adopted in this activity [4].

Telecommunications network design studies generally focus on minimizing investments, i.e., minimizing the number of equipment and the size of the cable network. In this sense, such studies are restricted to the use, adaptation, and development of optimization methods (e.g., integer programming [3, 11, 15, 45], combinatorial optimization [7], Fast Fourier Transform heuristic algorithms [17], Dijkstra algorithm [18, 19], and other, for instance, [46]). In the case of minimizing cable network size, planners look for the shortest path between network vertices (streets and customers) to establish a minimal network. Establishing this minimal network is an NP-hard problem known as Steiner's Minimum Tree [20]. However, path optimization algorithms [41] used to design the Steiner's network are heuristics that can yield suboptimal results $[47,48]$. Although no overall minimization of investments is guaranteed, these algorithms are widely used in network planning $[12,21]$ and are found both for planning the expansion of existing cable networks [1, 4, 7, 10, 11, 45] as well as for the planning of new cable networks [3, 15, 17, 40]. However, although some of these studies are concerned with the Internet demand forecast models [1, $7,11]$ and/or the geoprocessing of the features of the analyzed sites [17, 18, 43], these studies ignore the expand strategy and merely design an oversized network. In other words, these works focus exclusively on minimizing investments, ignoring the fact that that the most advantageous network strategy is defined by the return of investment ratio [25], that is, the ratio between the market and investments. In this

\section{Footnote 1 (continued)}

Therefore, it is considered in this research that: the number of mobile devices in homes is increasing [53]; users are increasingly adopting home Wi-Fi [54]; home Wi-Fi is used to offload traffic from mobile devices over fixed broadband, reducing costs and improving the quality of mobile services [49]. In short, Internet networks are to be designed to support some traffic from $5 \mathrm{G}$ network services. 


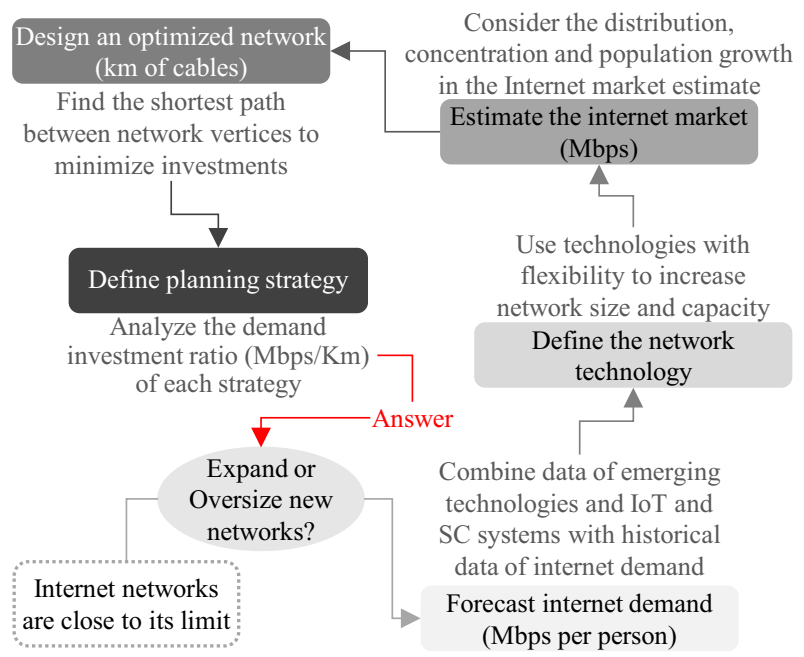

Fig. 1 The cable network planning scenario summary

sense, this research checks whether lower investments are reflected in higher return of investment ratio. This check is based on the cable network planning scenario presented in this section and briefly illustrated in the Fig. 1.

As illustrated in Fig. 1 the goal of this research is to answer which is the most advantageous cable network planning strategy using the market investment ratio information. Answering this question is a key element in the decision on investing in new networks because they are directly related to the return on investments made. This answer may be especially important for countries that rely on investments in new cable networks to increase their bandwidth capacity and, especially, to reduce their Internet access inequality. In Brazil, data from the National Telecommunications Agency [55] and the Brazilian Institute of Geography and Statistics or IBGE [56] reveal that $59 \%$ of customers served by cable networks are concentrated in the 55 largest cities ( $0.9 \%$ of the total) while Cities smaller than 100,000 inhabitants ( $94 \%$ of Brazilian cities) concentrate 26,688 customers or $0.1 \%$ of total accesses.

\section{Metodology}

The most advantageous cable network planning strategy was defined from three sets of procedures: estimating the Megabits per second (Mbps) in Brazil, estimating investments in kilometers $(\mathrm{Km})$ of cables, and analyzing the market investments ratio or $\mathrm{Mbps} / \mathrm{Km}$.

The procedure one "estimating the Megabits per second (Mbps) in Brazil" includes the following steps: I) Internet demand forecasting (Mbps per person), executed on Ninna-PCA and Microsoft Excel Software; II) geoprocessing of the characteristics of the city under analysis; III) creation of conservative, moderate, and aggressive decision scenarios; and IV) estimation of the Internet demand 
in Mbps, executed in Microsoft Excel. First, the Internet Demand Forecast Model combines the Principal Component Analysis (PCA) and Multiple Linear Regression (MLR) techniques [57]. PCA was applied to reduce the dimension/number of variables related to emerging technologies and the IoT and SC systems in order to avoid collinearity of independent variables in the forecast model [58]. The PCA model must satisfy three criteria [57]. First, average variance extracted (AVE) measures the variance of the variable that is explained by the principal component. Second, Kaiser-Meyer-Olkin (KMO) test measures whether the sample is suitable for the model, indicating the proportion of variables with common variances. Third, Bartlett's Test of Sphericity compares the PCA correlation matrix with the identity matrix, verifying the degree of redundancy between the model variables. The PCA model must include enough components to overcome the AVE threshold of 0.80 [59]. The KMO test greater than 0.6 indicates that sampling is adequate and the Bartlett's test less than 0.05 indicates that the correlation matrix is not an identity matrix [57]. In turn, the MLR was applied to find the Internet demand forecast function [57].

The MLR is a technique used to predict a variable (dependent) such is the Internet demand from a set of explanatory variables (independent). The MLR model is reliable when the adjusted $R$-squared (adjusted- $R^{2}$, significance test ( $F$-Test), and $p$-values criteria are satisfied [57]. The adjusted- $R^{2}$ indicates how much of the dependent variable can be explained by the independent variables, taking into account the number of independent variables in the model. In other words, it indicates the power of the forecasting model, with adjusted- $R^{2}$ equal to 0 indicating that the independent variables do not explain the dependent variable and that an adjusted- $R^{2}$ equal to 1 indicates the dependent variable is perfectly explained by the independent variables. The Test-F determine the statistical significance of the model. Test-F values less than 0.01 shows that the regression is statistically significant. The p-values tests the statistical significance of each independent variable of the model and must be less than $0.05[57,58]$. The dependent and independent variables used in the MLR to forecast the Internet demand are listed in Table 1.

The Internet $\mathrm{Mbps} /$ person forecast was made for a period of five years. The Internet market is estimated based on this forecast and the results of the second step: the geoprocessing of the characteristics of the city under analysis. This step was based on the georeferencing of population census data [62]. These data were updated and projected (five years ahead) using the respective estimates [56] and population projections [63] produced by the Brazilian Institute of Geography and Statistics (IBGE). In turn, the georeferencing of the data was based on: I) The proportion of the population present in each census tract [64]; II) number of vertices in each census tract, and; III) latitude and longitude of the vertices of the census tracts. The geoprocessing of the characteristics of the city under analysis yields the number of people in each census tract vertex or market point. The Internet market in Mbps is obtained by multiplying the Internet demand per person (Mbps/person) obtained in the forecast model by the number of people in each market point (person). Knowing the Internet market in the city, the question "expand or oversize?" is analyzed in the third step from the creation of different scenarios. The investment decision scenarios (conservative, moderate, and aggressive [65]) take as a criterion the minimum 


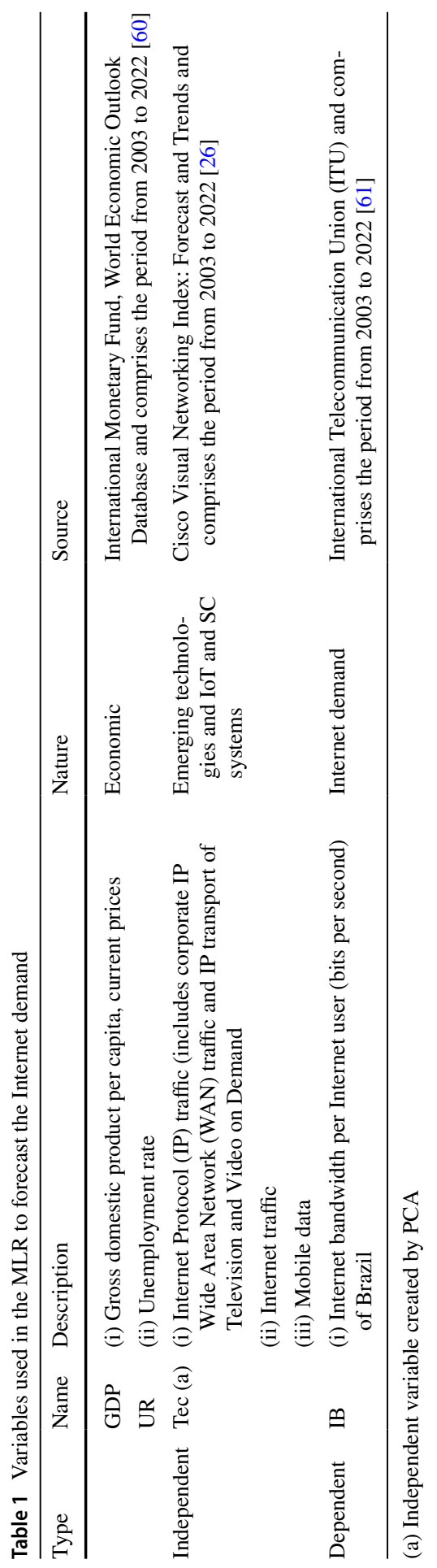


Internet market in Mbps accepted by the offerer. Thus, the decision scenario is considered conservative when the offerer requires a higher minimum Mbps, that is when the offerer imposes more restrictions to serve customers. In turn, the decision scenario is considered aggressive when the offerer accepts a lower minimum Mbps, that is when the offerer imposes fewer restrictions to serve customers. Finally, the decision scenario is considered moderate when the offerer is strategically positioned between the conservative and aggressive posture. An example of the use of minimum Mbps demands as a constraint investment by the offerer can be found in the work of Ljubic, Putz, and Salazar-González [45]. In the study, the minimum Mbps of conservative, moderate and aggressive scenario was defined respectively from the third, second and first quartile of Internet market per point (obtained by multiplying the results of steps 1 and 2). This gives the minimum market point Mbps definition of each of the three scenarios.

In this example, the Internet demand per person (Mbps per person) for each scenario is the same. The difference between the scenarios is the minimum market (Mbps) that the offerer is willing to invest. When the Mbps required by the offerer is the same, the difference between the scenarios would become the Mbps per person itself. In this case, the higher the Mbps per person, the greater the number of market points. As we will see, the scenario with the highest number of market points is the aggressive one followed by the moderate and conservative ones. In this sense, the aggressive scenario may represent the increase in Mbps per person caused by the COVID-19 [66] as more people access the Internet from home [67, 68]. The conservative scenario may represent a future retraction of Mbps per person as the independent variables used in the forecast model: UR and GDP will be affected in the medium term by the COVID-19 [69]. The International Monetary Fund estimates that the world GDP will retract by $3.0 \%$, and that the Brazilian UR will reach $14.7 \%$ of the population. Thus, there is an opportunity to interpret the aggressive scenario as the Internet demand that occurs during the COVID-19 and to interpret the conservative scenario as the Internet demand that occurs after the coronavirus.

The procedure two "Km investments in cables estimates" includes the following steps: I) design the Internet network for each strategy and scenario by applying the Dijkstra [19] and Steiner [20] algorithms; and II) measure the cable network for each strategy and scenario in Km, executed in the QGIS Software [70]. The cable networks planned were designed considering the market points in Mbps (obtained in the step 3 of procedure one), and the physical barriers (e.g. set of streets, squares, and avenues) of the unit of analysis (obtained from Digibase Digital Maps [71]). To design the oversize strategy network, we used Steiner's minimum tree algorithm [20] and the market points in Mbps from year 5. To design the expansion strategy network, two procedures were performed. The first procedure employs Steiner's minimum tree algorithm [20] and year 1 Mbps market points to design an initial network. The second procedure employs the Dijkstra algorithm [19], the initial network and the year 2 Mbps market points to design the first network expansion. Then the second procedure is repeated successively, employing Dijkstra [19], the initial network, the expanded networks and the Mbps market points of the year in question. Thus, six cable networks were designed: three cable networks for each of the two strategies. 


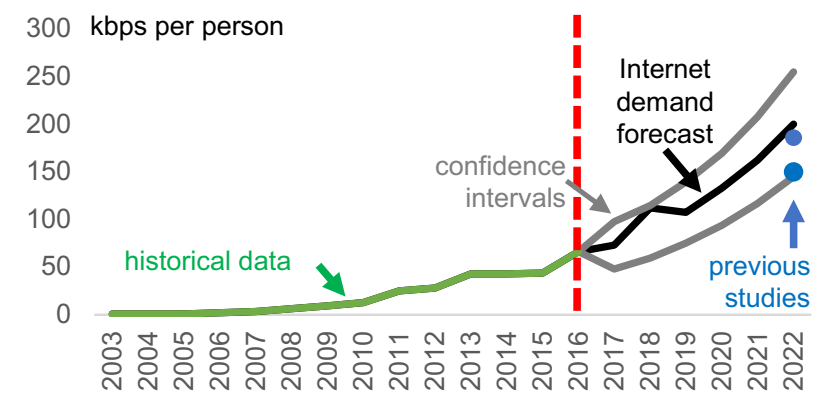

Fig. 2 Internet demand forecast

The procedure three "market investments ratio or Mbps/Km" analyzes the market investment ratio of the six designed cable networks. The answer for which is the most advantageous network planning strategy is obtained by comparing the market investment ratio $(\mathrm{Mbps} / \mathrm{Km})$ of each strategy for the three scenarios.

\section{Results and Discussions}

\subsection{Estimating the Megabits Per Second (Mbps) in Brazil}

This subsection includes the results of the following steps: (I) Internet demand forecasting (Mbps per person); (II) geoprocessing of the characteristics of the city under analysis; (III) creation of conservative, moderate, and aggressive decision scenarios; and (IV) estimate the Internet demand in Mbps.

The first results of the Internet demand forecasting step are related to the inclusion of the Emerging technologies and IoT and SC systems in the future Internet demand. The Tec variable, created from the PCA, had the AVE of 0.98 and KMO of 0.73 , and Bartlett's Test of less than 0.05 . This means that the variance explained by the principal component represents almost entirely the variables: (I) IP traffic; (II) Internet traffic; (III) mobile data. In turn, the KMO found indicates that the PCA sample size is appropriate for the analysis [58]. Finally, the Bartlett's test showed that the correlation matrix is not an identity matrix and therefore the variables are correlated. Thus, the Tec variable allows incorporating the effects of emerging services [32] and IoT and SC systems [33] as well as to avoid collinearity between independent variables in the forecasting model $[29,58]$. Considering the presence of these effects in the forecast model, it can be seen in Fig. 2 that Internet demand in Brazil will grow $78 \%$ in 5 years, reaching 199 kbps per person in 5 years.

In the forecast presented in the graph, it is observed that the Internet demand in Brazil is $33 \%$ and $7 \%$ higher than the forecasts presented in previous studies, respectively $[2,6]$. In this model, the adjusted- $R^{2}$ was 0.89 , showing that the Internet demand can very strongly predicted by the independent variable. F-test was less than 0.01 , showing that the regression is statistically significant. The p-values were 
Table 2 Market points (units) and Internet market (Mbps) per year by scenario

\begin{tabular}{llllll}
\hline Scenario/year & First & Second & Third & Fourth & Fifth \\
\hline Aggressive & 98 & 108 & 141 & 138 & 195 \\
& 2.875 & 3.399 & 6.113 & 5.818 & 8.567 \\
Moderate & 53 & 69 & 121 & 120 & 132 \\
& 1.821 & 2.461 & 5.651 & 5.408 & 7.094 \\
Conservative & 2 & 5 & 37 & 32 & 65 \\
& 105 & 270 & 2.390 & 2.052 & 4.415 \\
\hline
\end{tabular}

less than 0.05 , showing that the three independent variables (Tec, GDP and UR) are significant to explain the dependent variable.

The supply scenarios, defined on the basis of the first, second, and third quartile values obtained from the Internet demand forecast result (199 kbps per person) and the population at each demand point (IBGE [63]), were as follows: I) in the aggressive scenario (first quartile), the offerer, agrees to meet demands equal to or above $20.72 \mathrm{Mbps}$, restricting the cable network to meet $75 \%$ of the market points; II) in the moderate scenario (second quartile), the offerer agrees to meet demands equal to or above $27.06 \mathrm{Mbps}$, restricting the cable network to meet $50 \%$ of the market points; III) in conservative scenarios (third quartile) the offerer agrees to meet demands equal to or above $50.38 \mathrm{Mbps}$, restricting the cable network to meet $25 \%$ of the market points. Table 2 shows how the Internet market evolution for each scenario has evolved over the 5 years.

The market points are the vertices of the cable network. If, on the one hand, the number of market points indicates what the investment in the cable network will be, on the other hand, the Internet market signals the return on these investments. It should be noted that the difference of $27 \%$ between the Internet market in the moderate (53 Mbps) and aggressive (98 Mbps) scenarios is close to the percentage of increase in internet traffic observed as a result of COVID-19 [67, 68]. That is, although superficially, the aggressive scenario can be useful to understand how the changes caused by COVID-19 influence the planning of Internet networks.

\subsection{Estimating investments in $\mathbf{k m}$ of cables}

From the market points and applying the minimum path algorithms, the Internet networks were designed for the strategies of expanding and oversizing. Figure 3 compares the $\mathrm{Km}$ of cables for the aggressive scenario for expanding and oversizing. In this scenario, the Internet provider, by imposing a minor service constraint, plans the network to meet 195 market points in the fifth year.

In the fifth year of the aggressive scenario, the strategy of expanding implies $\mathrm{km}$ of cables $30.37 \%$ higher $(15.24 \mathrm{~km})$ compared to the oversize strategy. In turn, the strategy of expanding implies higher $\mathrm{km}$ of cables during the first 2 years. Figure 4 brings the comparison of the $\mathrm{Km}$ of cables in the moderate scenario based on the networks designed by the strategies of: expansion and oversizing. In this scenario, the Internet provider invests in a cable network to meet $50 \%$ of the 

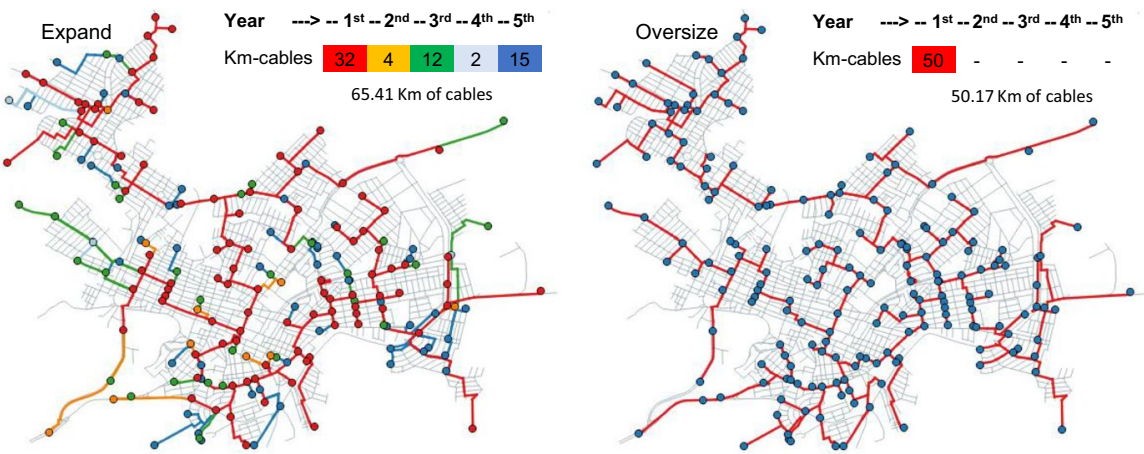

Fig. 3 Aggressive scenario-Internet market points $>20.72 \mathrm{Mbps}$
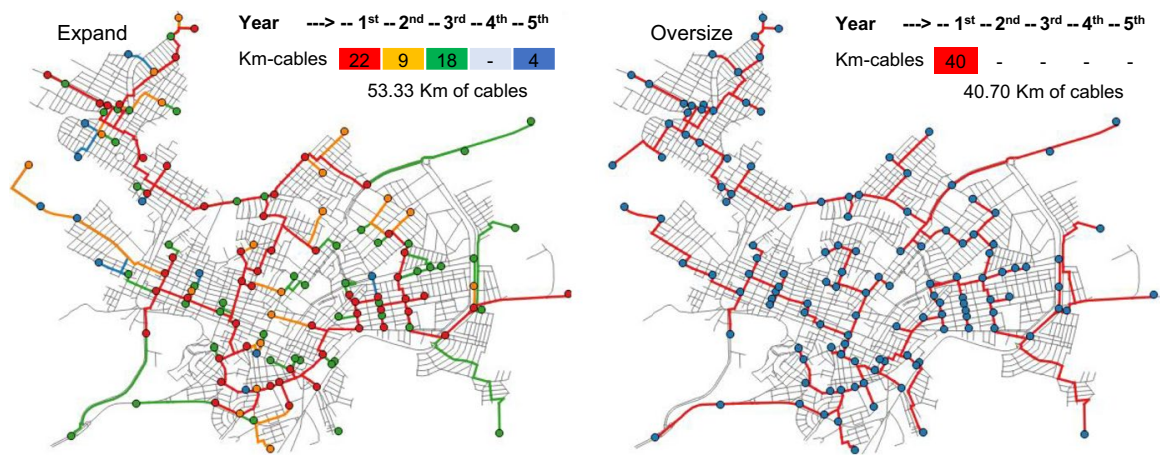

Fig. 4 Moderate scenario-Internet market points $>27.06 \mathrm{Mbps}$

market points. Thus, the networks designed in this scenario are based on points with Internet market above or above $27.06 \mathrm{Mbps}$. Considering this restriction, in the moderate scenario, 134 market points were met.

In the moderate scenario illustrated in Fig. 4, it is possible to notice a reduction in the number of market points compared to the aggressive scenario. With fewer market points to meet, the $\mathrm{Km}$ of cables difference from networks designed by the expansion $(53.33 \mathrm{~km})$ and oversizing $(40.70 \mathrm{~km})$ strategies decreased from $15.24 \mathrm{~km}$ (aggressive scenario) to $12.63 \mathrm{~km}$. However, the Km of cables difference from networks designed by expand and oversizing increased from $30.37 \%$ (aggressive scenario) to $31.03 \%$ in the moderate scenario. Figure 5 brings the comparison between the $\mathrm{Km}$ of cables for the conservative scenario in the strategies: expand and oversize. In this scenario, the Internet provider invests in a cable network to meet $25 \%$ of the market points. This percentage represents a scenario of greater restriction of supply, that is, the fulfillment of a smaller number of market points. Therefore, cable networks are designed to meet the 65 points that have Mbps market equal to or above 50.38 Mbps.

In conservative scenario, the lower number of Internet market points compared to aggressive (66\%) and conservative (51\%) scenario, are reflected in the smaller 

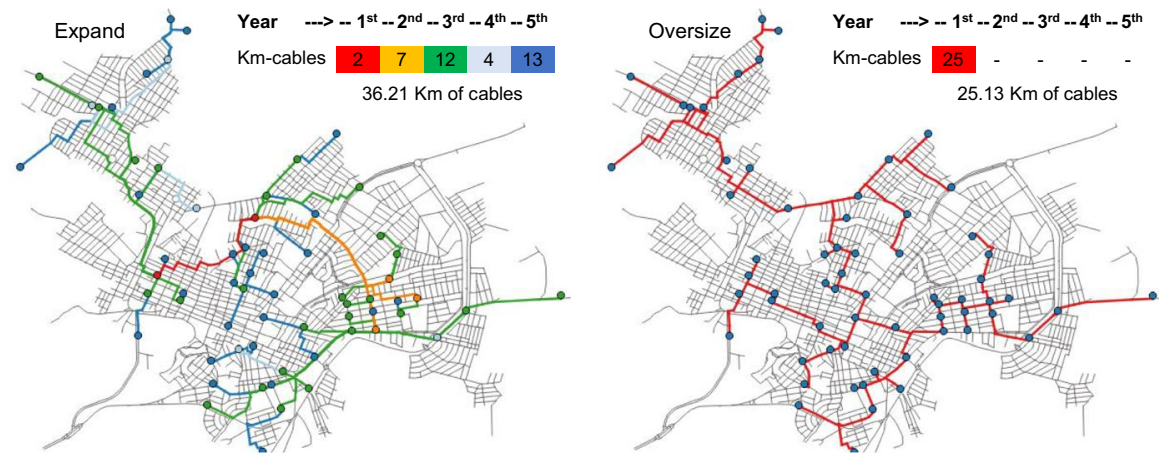

Fig. 5 Conservative scenario-Internet market points $>50.38 \mathrm{Mbps}$

cable network. While in the strategy of expanding the network designed in the conservative scenario was $36.21 \mathrm{~km}$ of cables, i.e. $55.35 \%$ and $47.27 \%$ smaller than the network designed by the same strategy in the moderate and aggressive scenarios, respectively. In the strategy of oversizing, the network designed in the conservative scenario was $25.13 \mathrm{~km}, 38.26 \%$, and $49.91 \%$ smaller than the networks designed by the same strategy in the moderate and aggressive scenarios, respectively. Among the three scenarios, the conservative scenario presents the smallest difference in cable investment $(\mathrm{Km}$ of cables $=11.08 \mathrm{~km})$. On the other hand, expanding the network in this scenario implies a $44.09 \%$ higher investment in cables than oversizing the network. This is the largest percentage difference in cable investment of the three analyzed scenarios.

These results show that oversizing the network is the most advantageous strategy for reducing $\mathrm{Km}$ cable costs, especially when the constraint on meeting demand (minimum Mbps) is less. This is because oversizing the network implies investments of $15.24 \mathrm{~km}, 12.63 \mathrm{~km}$, and $11.08 \mathrm{~km}$ smaller when the minimum Mbps are respectively 20.72 Mbps, 27.06 Mbps, and 50.38 Mbps. However, planners should consider that the percentage of cost savings in $\mathrm{Km}$ of cables is lower when the demand constraint is lower, $30.37 \%, 31.03 \%$, and $44.09 \%$, respectively. In summary, the results of the Km of cables suggest that oversizing the network implies lower investments regardless of the Internet supply scenario.

These results confirm that oversize is an optimal solution while the expand strategy is a kind of greedy optimization. However, it is still necessary to verify whether lower investments are reflected in a better return of investment ratio. This verification is performed by analyzing the market investment ratio of each strategy by scenario.

\subsection{Analyzing the Market Investments Ratio or $\mathrm{Mbps} / \mathrm{Km}$}

The $\mathrm{Mbps} / \mathrm{Km}$ of the expand and oversize strategies in the aggressive scenario equals $116 \mathrm{Mbps} / \mathrm{Km}$ in the fourth year. It means that the difference between the market investment ratio in the fourth year is equal to zero. Before that, the expand strategy presents an average of $22 \%$ higher $\mathrm{Mbps} / \mathrm{Km}$. In the fifth year, the Mbps/ 


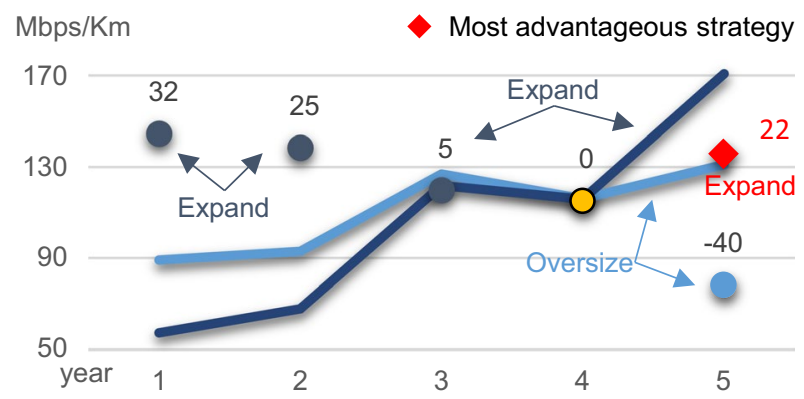

Fig. 6 Analysis of the market investment ratio of the aggressive scenario

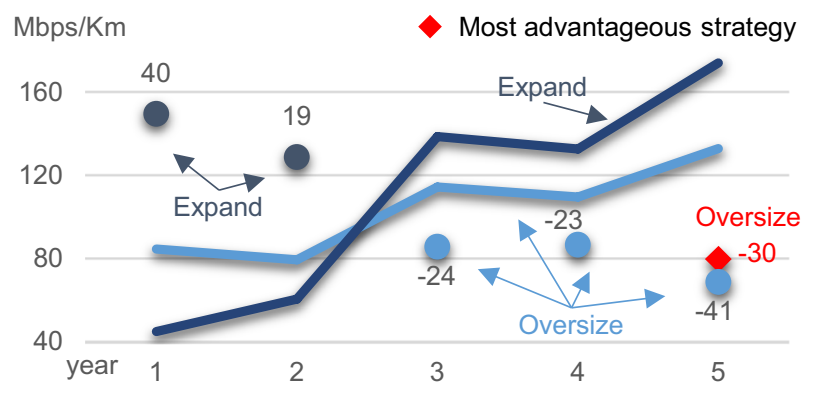

Fig. 7 Analysis of the market investment ratio of the moderate scenario

$\mathrm{Km}$ of the oversize strategy is $30 \%$ higher. In turn, the sum of the $\mathrm{Mbps} / \mathrm{Km}$ differences in the expand and oversize strategy is positive at $22 \mathrm{Mbps} / \mathrm{Km}$. This result suggests that expanding is the most advantageous strategy for the aggressive scenario when taken into account all the five years. Figure 6 presents a graph that summarizes the analysis of the market investment ratio for the aggressive scenario. The lines represent the $\mathrm{Mbps} / \mathrm{Km}$ of each strategy per year. The points represent the $\mathrm{Mbps} / \mathrm{km}$ difference between the expand and oversize strategies. Positive points indicate that the expand strategy is more advantageous, as they generate a higher $\mathrm{Mbps} / \mathrm{Km}$. The rhombus is the sum of the $\mathrm{Mbps} / \mathrm{Km}$ differences that indicates which is the most advantageous cable network planning strategy.

In the moderate strategy the results are not so different. The network designed in the fifth year by the oversize strategy is $21 \%(6 \mathrm{Mbps} / \mathrm{Km})$ higher than the network designed by the expand strategy. However, in this scenario, the oversizing the cable network is the best planning strategy not in the fifth year, but in the third year. As a result, the sum of the $\mathrm{Mbps} / \mathrm{Km}$ differences of the expand and oversize strategies is negative at $30 \mathrm{Mbps} / \mathrm{Km}$. This means that oversizing the network is the most advantageous strategy when taking into account the market investment ratio of the five years analyzed. Figure 7 summarizes the return of investment analysis of the moderate scenario which supports the understanding that the first years of the network's life are the most essential to return the investments made [25]. 


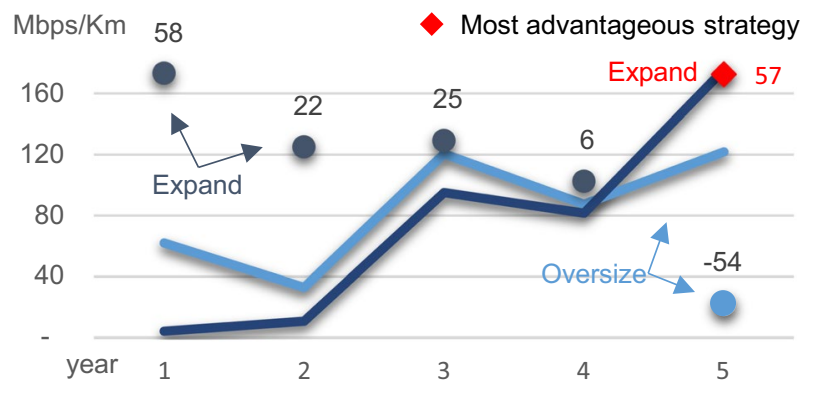

Fig. 8 Analysis of the market investment ratio of the conservative scenario

In fact, in the conservative scenario, the $\mathrm{Mbps} / \mathrm{Km}$ of the oversize strategy is also better than the strategy of expanding in the fifth year. But, just as in the aggressive scenario, the sum of the $\mathrm{Mbps} / \mathrm{Km}$ (rhombus) differences is positive, suggesting that expanding is also the most advantageous strategy for the conservative scenario.

The comparisons of the Mbps/Km per scenario shows that oversizing the cable network is the most advantageous strategy for meeting fifth-year demand in any scenario. However, the $\mathrm{Mbps} / \mathrm{Km}$ results also show that major supply constraints (high minimum Mbps) favor the strategy of expanding the network. This can be seen in Fig. 8, as the values of the $\mathrm{Mbps} / \mathrm{Km}$ in the oversize expand, are larger (positive results) than the $\mathrm{Mbps} / \mathrm{Km}$ of the oversize strategy (negative values).

The $\mathrm{Mbps} / \mathrm{Km}$ analysis suggests that oversizing networks are the best strategy for meeting medium to long-term demand and expanding is the best strategy for meeting short-term demand. However, in the conservative scenario, the strategy of expanding the network proves to be the most advantageous strategy until the fourth year, the $\mathrm{Mbps} / \mathrm{Km}$ of the oversizing (176 Mbps/Km) and expansion (122 Mbps/Km) strategies have the largest difference $(54 \mathrm{Mbps} / \mathrm{Km})$ between the three scenarios.

In short, the results of this research suggest that cable network planning strategies drive changes into the network designs, altering (positively or negatively) the volume of network investments. The results show more specifically that cable networks, if planned by the oversizing strategy, may be between $30 \%$ and $41 \%$ smaller than if planned by the expansion strategy. However, the results show that a smaller network is not always reflected in a higher market investment ratio $(\mathrm{Mbps} / \mathrm{Km})$. In the aggressive and conservative scenario, oversizing the network results in higher $\mathrm{Mbps} / \mathrm{Km}$ only in the fifth year. Considering the sum of $\mathrm{Mbps} / \mathrm{Km}$ over the five years, expanding the network is the most advantageous strategy in these two scenarios. These results show how important the market investment ratio in the early years influence the network planning strategy definition, and consequently the return the investments made [25].

Thus, this research contributes to open up new perspectives to increase the return the investments made in Internet networks. This means that network planners should not limit themselves to applying optimization methods, adding that expansion strategies are to be incorporated in their planning activities. Besides, the results not only reinforce the understanding that flexible network technologies $[15,18,21,30]$ are 
the recommended solutions for dynamic Internet demand scenarios [36], adding that these technologies offer different possibilities of network expansion strategies and design.

These contributions may be especially important to increase the supply of networks in developing countries. Thus, the results may be limited to the unit of analysis (city), leaving a question: what is the most advantageous network planning strategy in other cities? Thus, it is suggested to analyze the possible changes in the decision of the planning strategy when changing: the configuration of physical barriers (streets, avenues, etc.) present in each city, the demographic density found in each city, and the socioeconomic potential (presence of computer at home, income, etc.) of households.

\section{Conclusions}

This research shows that Internet demand growth maybe $7 \%$ higher than predicted in previous studies $[2,6]$. This evidence reinforces the understanding that emerging technologies [5, 32] and IoT and SC (Tec) systems [14, 28] stimulate the development of bandwidth-intensive applications and services [15]. This forecast of Internet demand is an important contribution for network planners as they rely on these forecasts to design Internet networks [45]. In this case, knowing that Internet demand will be greater than predicted contributes to network planners designing networks with the minimum cable network and the highest possible bandwidth and service capacity.

Besides, this research contributes to network planners being able to design smaller cable networks with sufficient bandwidth and/or service capacity to meet growing demand through different cable network planning strategy. Firstly, regardless of the planning strategy, flexible technologies (e.g., GPON [22, 23]) allow for increased network bandwidth and service capacity while optimizing methods (e.g., Dijkstra [19] and Steiner [20] algorithms) make it possible to minimize investments in cable networks $[3,15]$. Second, regardless of the scenario, oversizing the network reduces the cable network $(\mathrm{Km})$ by at least $30.37 \%$. Third, oversizing the network tends to be the most advantageous strategy when it has higher $\mathrm{Mbps} / \mathrm{Km}$ from the third year. Fourth, expanding tends to be the most advantageous strategy when it has higher $\mathrm{Mbps} / \mathrm{Km}$ up to the fourth year.

Although these results are limited to the analyzed city, this research opens new perspectives for studies that seek to minimize investments in the cable network. In this sense, future studies may explore the effects of planning strategies in defining the positions and number of optical network splitters [18] or the amount of fiber in the network cables [17]. Another possibility is to explore possible changes in the definition of the most advantageous network planning strategy when using other network design optimization methods [3, 15, 45, 46]. Finally, it is suggested to analyze the hypothesis that changes in the configuration of the physical barriers of cities (e.g. avenues, streets, and bridges) or the population distribution/population density alter the decision of the most advantageous planning strategy. 
Funding The work of Matheus Pereira Libório was supported by the Coordenação de Aperfeiçoamento de Pessoal de Nível Superior, Brazil (CAPES), under Finance Code 001. The work of Petr Iakovlevitch Ekel was supported by the Brazilian National Council for Scientific and Technological Development (Conselho Nacional de Desenvolvimento Científico e Tecnológico, CNPq) under grant 311032/2016-8 and by Companhia Vale - Brasil (Vale) - P\&D 2019-2022 "Pesquisa em Planejamento e Suporte a Tomada de Decisão". The work of Gustavo Luís Soares was supported by the Brazilian National Council for Scientific and Technological Development (Conselho Nacional de Desenvolvimento Científico e Tecnológico, CNPq) under grant 406011/2016-8 and by Companhia Vale - Brasil (Vale) - P\&D 20192022 "Pesquisa em Planejamento e Suporte a Tomada de Decisão". The work of Thiago Melo MachadoCoelho was supported by the Brazilian National Council for Scientific and Technological Development (Conselho Nacional de Desenvolvimento Científico e Tecnológico, CNPq) under grant 406011/2016-8.

Availability of Data and Material Not applicable.

\section{Compliance with Ethical Standards}

Conflicts of interest The authors declares that there is no conflict of interest.

\section{References}

1. Todd, B., Doucette, J.: A novel long term telecommunication network planning framework. J. Netw. Syst. Manage. 25(1), 47-82 (2017)

2. M. P. Libório, S. Laudares, I. S. Silva, R. da Cunha Costa, P. Bernardes, and P. S. Saviott, "Dinâmica espaço tempo da demanda por Internet: As cidades do futuro no cenário brasileiro de telecomunicações," Raega-O Espaço Geográfico em Análise, vol. 44, pp. 08-20, 2018

3. K. F. Poon, A. Ouali, and B.-S. Lee, "Physical layer design of optical networks with practical considerations," in Industrial Engineering and Engineering Management (IEEM), 2014 IEEE International Conference on. IEEE, 2014, pp. 1342-1346

4. Kretsis, A., Christodoulopoulos, K., Kokkinos, P., Varvarigos, E.: Planning and operating flexible optical networks: algorithmic issues and tools. IEEE Commun. Mag. 52(1), 61-69 (2014)

5. Li, J., Shen, G.: Cost minimization planning for greenfield passive optical networks. Journal of Optical Communications and Networking 1(1), 17-29 (2009)

6. Libório, M.P., Machado-Coelho, T.M., Bernardes, P., Machado, A.M.C., Ekel, P.Y., Soares, G.L.: Forecasting Internet demand using public data: a case study in brazil. IEEE Access 6, 65974-65980 (2018)

7. Ghani, N., Liu, Q., Gumaste, A., Lankford, J., Shami, A., Assi, C.M., et al.: Value-added services in next-generation SONET/SDH networks. IEEE Commun. Mag. 46(11), 64-73 (2008)

8. Batagelj, B., Janyani, V., Tomažic, S.: Research challenges ` in optical communications towards 2020 and beyond. Informacije Midem 44(3), 177-184 (2015)

9. Haddaji, N., Nguyen, K., Cheriet, M.: Towards end-to-end integrated optical packet network: empirical analysis. Optical Switching and Networking 27, 18-39 (2018)

10. Papanikolaou, P., Christodoulopoulos, K., Varvarigos, E.: Optimization techniques for incremental planning of multilayer elastic optical networks. IEEE/OSA J. Opt. Commun. Networking 10(3), 183-194 (2018)

11. G. V. Arévalo and R. Gaudino, "A techno-economic network planning tool for pon deployment including protection strategies," in 2017 19th International Conference on Transparent Optical Networks (ICTON). IEEE, 2017, pp. 1-4

12. Shah, G.A., Hussain, S.: Impacts of planning on telecom access network developmental project: a case study of ptcl. Journal of Social and Organizational Analysis 2, 20-36 (2016)

13. Sudtasan, T., Mitomo, H.: The Internet of things as an accelerator of advancement of broadband networks: a case of thailand. Telecommunications Policy 42(4), 293-303 (2018)

14. Mycek, M., Pióro, M., Zotkiewicz, M.: Mip model for effi- ${ }^{-}$cient dimensioning of real-world FTTH trees. Telecommunication Systems 68(2), 239-258 (2018) 
15. S. A. Fernandez, A. A. Juan, J. de Armas Adrián, D. G. e Silva, and D. R. Terrén, "Metaheuristics in telecommunication systems: network design, routing, and allocation problems," IEEE Systems Journal, no. 99, pp. 1-10, 2018

16. Gloaguen, C., Cali, E.: Cost estimation of a fixed network deployment over an urban territory. Ann. Telecommun. 73(5-6), 367-380 (2018)

17. A. Ouali, K. F. Poon, B.-S. Lee, and K. Al Romaithi, "Towards achieving practical GPON FTTH designs," in Computer Aided Modelling and Design of Communication Links and Networks (CAMAD), 2015 IEEE 20th International Workshop on. IEEE, 2015, pp. 108-113

18. Dijkstra, E.W.: A note on two problems in connexion with graphs. Numer. Math. 1(1), 269-271 (1959)

19. Hwang, F.K., Richards, D.S.: Steiner tree problems. Networks 22(1), 55-89 (1992)

20. Zotkiewicz, M., Mycek, M., Tomaszewski, A.: Profitable areas in large-scale FTTH network optimization. Telecommunication Systems 61(3), 591-608 (2016)

21. I. Recommendation, "G984. 2,"," Gigabit-capable passive optical networks (GPON): Physical media dependent (PMD) layer specification, 2003

22. ITU, "984.1: Gigabit-capable passive optical networks (GPON): General characteristics," International Telecommunication Union, Tech. Rep., 2008

23. E. Al Nuaimi, H. Al Neyadi, N. Mohamed, and J. Al-Jaroodi, "Applications of big data to smart cities," Journal of Internet Services and Applications, vol. 6, no. 1, p. 25, 2015

24. J. Pesic, T. Zami, P. Ramantanis and S. Bigo, "Faster return of investment in WDM networks when elastic transponders dynamically fit ageing of link margins," in 2016 Optical Fiber Communications Conference and Exhibition OFC, IEEE, 2016, pp. 1-3

25. Cisco, "Visual networking index: Forecast and trends, 2017-2022," Cisco Systems Incorporation, Tech. Rep., 2018

26. R. Kenny and T. Broughton, "Domestic demand for bandwidth an approach to forecasting requirements for the period 20132023," Broadband Stakeholder Group, Tech. Rep., 2013

27. D. Kish, I. Keene, S. Fabre, and A. K. Sharma, "Forecast analysis: Carrier network infrastructure, worldwide, 2010-2017," 2013

28. Kim, H., Swanson, N.R.: Forecasting financial and macroeconomic variables using data reduction methods: new empirical evidence. Journal of Econometrics 178, 352-367 (2014)

29. Kulkarni, S., El-Sayed, M.: FTTH-based broadband access technologies: key parameters for cost optimized network planning. Bell Labs Technical Journal 14(4), 297-309 (2010)

30. Karagiannis, T., Molle, M., Faloutsos, M.: Long-range dependence-ten years of Internet traffic modeling. IEEE Internet Comput. 8(5), 2-9 (2004)

31. Jin, J., Gubbi, J., Marusic, S., Palaniswami, M.: An information framework for creating a smart city through Internet of things. IEEE Internet of Things journal 1(2), 112-121 (2014)

32. Lee, I., Lee, K.: The Internet of things (IoT): applications, investments, and challenges for enterprises. Bus. Horiz. 58(4), 431-440 (2015)

33. Maple, C.: Security and privacy in the Internet of things. Journal of Cyber Policy 2(2), 155-184 (2017)

34. I. Makhdoom, M. Abolhasan, J. Lipman, R. P. Liu, and W. Ni, "Anatomy of threats to the Internet of things," IEEE Communications Surveys \& Tutorials, 2018

35. Abbas, H.S., Gregory, M.A.: The next generation of passive optical networks: a review. Journal of network and computer applications 67, 53-74 (2016)

36. J. Y. Khan, D. Chen, and O. Hulin, "Enabling technologies for effective deployment of Internet of things (IoT) systems," Australian Journal of Telecommunications and the Digital Economy, vol. 2, no. 4, 2014

37. Hua, L., Junguo, Z., Fantao, L.: Internet of things technology and its applications in smart grid. TELKOMNIKA Indonesian Journal of Electrical Engineering 12(2), 940-946 (2014)

38. Na, H.S., Lee, D., Hwang, J., Lee, C.: Research on the mutual relations between isp and asp efficiency changes for the sustainable growth of the Internet industry. Appl. Econ. 50(11), 1238-1253 (2018)

39. O. Hanseth and K. Lyytinen, "Design theory for dynamic complexity in information infrastructures: the case of building Internet," in Enacting Research Methods in Information Systems. Springer, 2016, pp. 104-142

40. X. Han, V. Martinez, and A. Neely, "Service in the platform context: A review of the state of the art and future research," in Collaborative Value Co-creation in the Platform Economy. Springer, 2018, pp. 1-27 
41. P. K. Dalela, S. Basu, S. Majumdar, A. Yadav, A. Singh, N. Nagpal, and V. Tyagi, "Geo-intelligence based terrainaware mobile backhaul planning for rural india," in 2014 IEEE International Conference on Advanced Networks and Telecommuncations Systems (ANTS). IEEE, 2014, pp. 1-6

42. Phillipson, F.: Roll-out of reliable fiber to the cabinet: an interactive planning approach. IEEE/OSA J. Opt. Commun. Networking 6(8), 705-717 (2014)

43. Mack, E.A., Maciejewski, R.: A profile of visual analytical toolkits for understanding the spatiotemporal evolution of broadband provision. Telecommunications Policy 39(3-4), 320-332 (2015)

44. Ljubic, I., Putz, P., Salazar-González, J.-J.: A mip-based' approach to solve the prize-collecting local access network design problem. Eur. J. Oper. Res. 235(3), 727-739 (2014)

45. Rentao, G., Xiaoxu, L., Hui, L., Lin, B.: Evolutional algorithm based cascade long reach passive optical networks planning. China Commun. 10(4), 59-69 (2013)

46. M. Neteler, D. Beaudette, P. Cavallini, L. Lami, and J. Cepicky, "Grass GIS," in Open source approaches in spatial data handling. Springer, 2008, pp. 171-199

47. A. Jolma, D. P. Ames, N. Horning, H. Mitasova, M. Neteler, A. Racicot, and T. Sutton, "Opensource tools for environmental modeling," in Springer Handbook of Geographic Information. Springer, 2011, pp. 597-619

48. Forge, S., Blackman, C.: Europe's 5G field of dreams: if we build it, will they come? Digital Policy, Regulation and Governance 19(5), 337-352 (2017)

49. Oughton, E., Frias, Z., Russell, T., Sicker, D., Cleevely, D.: Towards 5G: scenario-based assessment of the future supply and demand for mobile telecommunications infrastructure. Technol. Forecast. Soc. Chang. 133, 141-155 (2018)

50. Behrens, C., Krauß, S., Weis, E., Breuer, D.: Technologies for convergence of fixed and mobile access: an operator's perspective. Journal of Optical Communications and Networking 10(1), 37-42 (2018)

51. S. Izydorek, A. Gravey and R. Tadayoni, "How, when and where can Fixed Wireless Access compete with FTTH?", in 2019 European Conference on Networks and Communications (EuCNC). IEEE, 2019, pp. 63-68

52. Ericsson, "5G Consumer Potential: Busting the myths around the value of 5G for consumers," An Ericsson Consumer \& Industry Lab Insight Report, May 2019, p. 1-15 https://www.ericsson. com/498f26/assets/local/reports-papers/consumerlab/reports/2019/5g-consumer-potential-repor t.pdf. Mar 25, 2020

53. K. Fukuda, H. Asai and K. Nagami, "Tracking the evolution and diversity in network usage of smartphones", in 2015 Internet Measurement Conference. ACM, 2015, pp. 253-266

54. Anatel, "Acessos - banda larga fixa," National Telecommunications Agency, Tech. Rep., 2018. http://www.anatel.gov.br/dados

55. IBGE, "Estimativas de população 2018," Brazilian Institute of Geography and Statistics, Tech. Rep., 2018. https://www.ibge.gov.br/estatisticasnovoportal/sociais/populacao/9103-estimativas-depop ulacao.html

56. Hair, J., Black, W., Babin, B., Anderson, R., Tatham, R.: Multivariate data analysis, 8th Edition. Cengage, U.K. (2019)

57. A. Afifi, S. May, and V. A. Clark, Practical multivariate analysis. CRC Press, 2011

58. Jolliffe, I.: Discarding Variables in a Principal Component Analysis. I: artificial Data. J. Roy. Stat. Soc.: Ser. C (Appl. Stat.) 21, 160-173 (1972). https://doi.org/10.2307/2346488

59. IMF, "World Economic and Financial Surveys: World Economic Outlook Database," International Monetary Fund, Tech. Rep., 2018. https://www.imf.org/en/Publications/SPROLLS/worldeconomicoutlook-databases

60. ITU, "Measuring the information society report 2017," International Telecommunication Union, Tech. Rep., 2017. https://www.itu.int/en/ITU-D/Statistics/Documents/publications/misr2017/ MISR2017_Volume2.pdf

61. “Censo demográfico 2010," Brazilian Institute of Geography and Statistics, Tech. Rep., 2010. https ://55.ibge.gov.br/

62. “Projeção de população 2019-2022," Brazilian Institute of Geography and Statistics, Tech. Rep., 2018. https://www.ibge.gov.br/estatisticasnovoportal/sociais/populacao/9109-projecao-dapopulaca o.html? $=\& \mathrm{t}=$ downloads

63. IBGE, "Bases cartográficas: malhas digitais," Brazilian Institute of Geography and Statistics, Tech. Rep., 2010. https://mapas.ibge.gov.br/bases-e-referenciais/basescartograficas/malhas-digitais

64. M. Scherling, Practical risk management for the CIO. CRC Press, 2016 
65. F. He, Y. Deng and W. Li, “Coronavirus Disease 2019 (COVID-19): What we know?" Journal of medical virology. pp. 1-7, 2020

66. M. Beech, "COVID-19 Pushes Up Internet Use 70\% And Streaming More Than 12\%, First Figures Reveal". $\quad$ www.forbes.com/sites/isabeltogoh/2020/04/24/united-just-ordered-flight-attendants-towear-masks-heres-why-passengers-could-be-next/\#2cc59476d439. Mar 25, 2020

67. J. Davidson, "Global Internet Traffic Spiking? Add Bandwidth with Cisco's Flexible Consumption Model”, 2020. https://blogs.cisco.com/news/global-Internet-traffic-spiking-add-bandwidth-withciscos-flexible-consumption-model, Mar 25, 2020

68. IMF, International Monetary Fund, "World Economic Outlook, The Great Lockdown", Tech. Rep., 2020. https://www.imf.org/ /media/Files/Publications/WEO/2020/April/English/Foreword.ashx. Mar 25, 2020

69. Reyes, R., Zhao, R., Machuca, C.M.: Advanced dynamic migration planning toward FTTH. IEEE Commun. Mag. 52(1), 77-83 (2014)

70. Q. D. Team et al., "QGIS geographic information system," Open Source Geospatial Foundation Project, Versão, vol. 2, no. 7, 2015

71. Digibase, "Mapa Digital das Ruas de São Sebastião do Paraíso, MG Brasil,” Digibase Mapa Digitais, Tech. Rep., 2010

Publisher's Note Springer Nature remains neutral with regard to jurisdictional claims in published maps and institutional affiliations.

\title{
Affiliations
}

\section{Matheus Pereira Libório ${ }^{1}$ - Petr lakovlevitch Ekel ${ }^{1}[$ - Renata de Mello Lyrio ${ }^{2,3}$ - Patrícia Bernardes ${ }^{1}\left[\right.$. Gustavo Luís Soares ${ }^{1}[$. Thiago Melo Machado-Coelho ${ }^{3}$}

\author{
Matheus Pereira Libório \\ m4th32s@gmail.com \\ Petr Iakovlevitch Ekel \\ ekel@pucminas.br \\ Renata de Mello Lyrio \\ lyriorenata@hotmail.com \\ Patrícia Bernardes \\ patriciabernardes@pucminas.br \\ Gustavo Luís Soares \\ gsoares@pucminas.br \\ 1 Pontifical Catholic University of Minas Gerais, Belo Horizonte 30535-012, Brazil \\ 2 Federation of Industries of Minas Gerais, Belo Horizonte 35501-001, Brazil \\ 3 Federal University of Minas Gerais, Belo Horizonte 31270-901, Brazil
}

